DOI: $10.15593 / 2224-9354 / 2019.2 .16$

УДК 336.225

\author{
Н.А. Толстоброва, Е.К. Климова
}

\author{
ВЛИЯНИЕ ИНСТРУМЕНТОВ НАЛОГОВОГО \\ АДМИНИСТРИРОВАНИЯ НА ДЕЛОВУЮ АКТИВНОСТЬ
}

Данное исследование направлено на анализ последствий законодательных изменений в сфере ведения бизнеса в России в условиях санкций, когда необходимость либерализации бизнеса и повышения деловой активности сопровождается активизацией налогового администрирования. Основным направлением в сфере налогового администрирования становится повышение эффективности системы налогообложения, контрольно-надзорной деятельности и нормативной конкретизации организационно-правовых форм ведения бизнеса. Более жесткая трактовка условий функционирования такой формы предприятия, как общество с ограниченной ответственностью, не способствует привлечению населения в бизнес. С ужесточением субсидиарной ответственности, а также применением статьи 54.1 НК РФ усилятся надзорные функции государства, увеличится фискальная нагрузка.

Использованы общенаучные подходы, сравнительные и экономико-статистические методы. Рассмотрены проблемы государственной поддержки бизнеса. Проведен анализ влияния государственных мер законодательного и нормативного характера на функционирование предприятий малого и среднего бизнеса. Обобщение и конкретизация практики налогового администрирования позволили установить взаимосвязь регистрации внесения/исключения в государственный реестр ЕГРЮЛ и ЕГРИП с заявительным принципом осуществления предпринимательской деятельности. Внедрение технологических новинок в систему налогового учета и усиление субсидиарной ответственности отфильтровали участников бизнеса, которые номинально учитывались в реестрах. Представленные результаты анализа статистических данных свидетельствуют о сокращении числа юридических лиц (основная часть выбывающих организаций относится к форме ООО). Это связано с оптимизацией процедур регистрации юридических лиц, с повышением эффективности применения процедуры банкротства. Выявлены тенденции в развитии практики налогового администрирования. Обоснована необходимость мониторинга всей совокупности государственных мер и факторов, влияющих на предпринимательскую активность.

Ключевые слова: налоговый контроль, налоговое администрирование, регистрация бизнеса, предпринимательство, общество с ограниченной ответственностью, субсидиарная ответственность.

В 2018 году исполняется 10 лет фразе «Хватит кошмарить бизнес», но нагрянувший глобальный кризис 2008 года, неблагоприятная конъюнктура глобальных сырьевых рынков, а в дальнейшем ситуация внешнеполитическая после крымских событий 2014 года, повлекших санкционный режим, привели к целому ряду законодательных изменений в политике налогового регулирования, в котором администрирование стало приоритетным [1,2].

(c) Толстоброва Н.А., Климова Е.А., 2019

Толстоброва Надежда Александровна - канд. экон. наук, доцент кафедры экономики и финансов ФГБОУ ВО «Пермский национальный исследовательский политехнический университет», e-mail: tolstobrova@mail.ru.

Климова Елена Калисатаровна - старший преподаватель кафедры экономики и финансов ФГБОУ ВО «Пермский национальный исследовательский политехнический университет», e-mail: klimovalk@gmail.com. 
Уточняя термин «налоговое администрирование», используемый в нормативно-правовых актах, авторы придерживаются мнения, широко представленного в научных исследованиях [3]. Налоговое администрирование - деятельность налоговых органов, направленная на обеспечение исполнения налогового законодательства юридическими и физическими лицами. Она включает в себя налоговый учет, прием налоговой и финансовой отчетности, в ряде случаев и расчет налогов, контроль над отчетностью и уплатой налогов, иные меры, которые также тесно связаны с обеспечением поступления налогов в бюджетную систему, исполнением норм налогового законодательства. Налоговый контроль тесно связан с налоговым администрированием, он возможен при наличии системы налогового администрирования и рассматривается как ее элемент.

В процессе сбора и обработки информации о развитии практики налогового контроля по материалам публикаций в научных и специализированных изданиях, нормативно-правовых документов, аналитических отчетов и статистических данных были выявлены следующие тенденции и подходы:

во-первых, неизбежность проведения налоговых реформ в крупнейших странах, обеспечивающих поддержку населения со средними доходами, снижающих налоговую нагрузку на бизнес для обеспечения деофшоризации бизнеса; ярким проявлением стали налоговые реформы 2017 года Трампа (США) и Моди (Индия) [4, с. 88-89];

во-вторых, существенное влияние на организацию и результаты налогового контроля оказывает процесс перехода к цифровой экономике, автоматизация привела к сокращению выездных проверок, а сроки проведения камеральных на законодательном уровне были сокращены с трех до двух месяцев $[5$, c. 53-62];

в-третьих, реализации риск-ориентированного подхода в налоговом администрировании будет способствовать мониторинг контрольно-надзорной деятельности ФНС [6, с. 33]; а также внедрение критерия экономической целесообразности для предпроверочного анализа налогоплательщиков [7, с. 61];

в-четвертых, установление на законодательном уровне обязательства крупным компаниям иметь формализованную систему внутреннего налогового контроля, результаты которого, подтвержденные независимым аудитором, должны стать основанием для освобождения компании от налоговой проверки $[8,9]$.

Значительно превышающий рост налоговых поступлений с 2013 по 2017 год в консолидированный бюджет Российской Федерации почти в 1,6 раза, при реальном росте ВВП всего на 1,2 \% [10], приводит к суждениям в обществе об усилении налоговой нагрузки, вызывает тревожность и падение деловой активности, о динамике которой можно сформировать суждения по данным о регистрации и внесения/исключения в государственных реестpax ЕГРЮЛ и ЕГРИП. 
Очень часто формируется общественное сознание без учета многообразия факторов, которые приводят к изменению статистических данных отдельных показателей. Многофакторность экономических процессов должна стать основным принципом при внесении изменений на всех уровнях. В преддверии изменения ставки НДС на $2 \%$ были выдвинуты экспертные заключения о прогнозируемом росте цен с 6 до $10 \%$, такой разрыв аргументируется в первую очередь изменением величин спроса и предложения. Манипуляция налоговыми ставками в сторону повышения, особенно косвенных налогов, порождающих регрессию, приводит к негативным явлениям в краткосрочном периоде.

Следует придерживаться заявленного приоритета в стратегических целях ФНС России: повышение эффективности использования инструментов налогового администрирования, направленных на мотивирование налогоплательщиков к добровольной уплате налогов и применению в сделках цеен, соответствующих рыночным [11].

Целью данного исследования стало выявление влияния некоторых направлений налогового администрирования на деятельность бизнеса. В процессе исследования проведен анализ динамики данных о регистрации юридических лиц. Статистические данные отражают состояние и тенденции деловой активности бизнеса. Соотнесение выводов анализа с экспертными оценками, с анализом принимаемых нормативно-правовых решений в сфере налогового администрирования позволило выявить направления оптимального подхода к организации горизонтального мониторинга ФНС РФ. Горизонтальный мониторинг следует рассматривать как наиболее эффективный механизм для ухода от формализации риск-ориентированного налогового контроля, он усиливает аналитический метод в налоговом администрировании. Недопустима практика манипуляции налоговыми ставками, так как она порождает существенные сбои в налоговой системе в целом.

Одним из важнейших направлений развития реального сектора экономики является формирование стабильного сегмента малого и среднего бизнеca, но опросы общественного мнения свидетельствуют, что только 4 \% граждан в РФ готовы заниматься своим делом. По мнению экспертов, эта цифра должна быть втрое больше, чтобы экономика развивалась нормально. Эксперты считают, что одна из главных проблем - избыточный контроль со стороны государства. Более 200 контрольно-надзорных функций для бизнеса, из них около 160 на федеральном уровне. Для сравнения, в Европе таких функций около полусотни. Иными словами, у нас слишком много проверяющих и слишком мало делателей [12].

С одной стороны, имеет место создание условий и совершенствование финансово-экономического регулирования в целях развития малого и среднего предпринимательства. Постоянно расширяется государственная поддерж- 
ка формирования инфраструктуры для развития малого и среднего бизнеса. Для эффективной реализации государственной поддержки, в первую очередь, необходимо создание действенных инструментов и механизмов. Причем их создание необходимо как на федеральном, так и на региональном уровнях $[13$, c. 208$]$.

23 октября 2018 года в Москве на площадке ВДНХ состоялся ежегодный предпринимательский форум организации «Опоры России» на тему «Малый бизнес - национальный проект!». В предстоящем периоде малые предприятия и самозанятые граждане будут освобождены от плановых проверок, объем отчетности ограничат, а госзакупки у малого и среднего бизнеса к 2024 году должны достичь 5 трлн руб. В ближайшие шесть лет вклад малого и среднего бизнеса в ВВП России должен превысить 30 \%, а позднее достичь 40 \%. Продлить мораторий на проверки малых компаний и самозанятых на два года поручил Президент РФ. Речь шла о предельном упрощении всех процедур создания и ведения бизнеса, сохранении баланса интересов общества и государства [14].

Правительство одобрило паспорт Национального проекта по поддержке малого и среднего бизнеса, который начнет реализовываться с 2019 года и будет определять направления развития малого бизнеса в России до 2024 года [15]. Национальный проект отвечает ключевым задачам по обеспечению достижения показателя увеличения численности занятых в секторе МСП до 25 млн чел. к 2024 году. Необходимо увеличить среднюю продолжительность жизни предприятий малого и среднего бизнеса с 5 лет сегодня до 6-7 лет в 2024 году. А также необходимо вовлекать как можно большее количество граждан с соответствующими компетенциями в предпринимательскую деятельность.

Говоря об эффективности предусмотренных государством мер поддержки бизнеса, стоит отметить, что доступные к использованию налоговые льготы очень часто отличаются сложностью и чрезвычайной ограниченностью их получения. Низкая эффективность действующей системы налогообложения выражается в большом количестве всевозможных налогов, непрозрачности и возрастающей сложности их расчета, необоснованных частых проверках контролирующих органов. Практика показывает, что почти половина хозяйствующих субъектов вообще не обращается к налоговым льготам во избежание привлечения лишнего внимания налоговых органов и проведения необоснованных проверок, нежелания бумажной волокиты и доказывания права на ту или иную льготу [16, с. 237].

Наболевший вопрос для бизнеса - работа контрольно-надзорных органов. Реформа контроля и надзора продолжается, прежде всего она направлена на повышение прозрачности контрольной деятельности. Продление надзорных каникул должно сопровождаться совершенствованием и расширением линейки инструментов поддержки малого и среднего бизнеса. 
В целом на сегодня сформулированы новые меры поддержки предпринимательства. Но, с другой стороны, если посмотреть на законодательные инициативы в сфере налогообложения, например, появление дополнения к статье 54 НК РФ, то это именно усиление надзора и контроля за использованием налогоплательщиком своих прав. Статья 54.1 устанавливает пределы осуществления прав по исчислению налоговой базы и (или) суммы налога, сбора, страховых взносов $[2,17]$.

Продекларировано, что указанная норма фактически определяет условия, препятствующие созданию налоговых схем, направленных на незаконное уменьшение налоговых обязательств. НК РФ конкретизирует и приводит примеры: это создание схемы «дробления бизнеса», направленной на неправомерное применение специальных режимов налогообложения; совершение действий, направленных на искусственное создание условий по использованию пониженных налоговых ставок, налоговых льгот, освобождения от налогообложения; создание схемы, направленной на неправомерное применение норм международных соглашений во избежание двойного налогообложения [17].

Налогоплательщики связывают с дополнением статьи 54.1 НК РФ надежды на ограничение пределов ответственности только умышленными действиями, направленными на получение необоснованной налоговой выгоды и не связанными с недобросовестными действиями своих контрагентов. Судебная практика не оправдывает надежд налогоплательщиков.

Наибольшее распространение в современной экономике РФ имеет такая организационно-правовая форма предпринимательской деятельности, как общество с ограниченной ответственностью (ООО). В 2017 году законодатель решил ужесточить субсидиарную ответственность, чтобы легче было заставить недобросовестных предпринимателей платить по долгам разоренной ими компании, что привело к сокращению численности регистрируемых юридических лиц (табл. 1) [18].

Общее количество юридических лиц, а именно коммерческих организаций до 2016 года выросло на 30 \%, при этом количество ООО увеличилось значительнее, на 50 \%. Начиная с 2016 года тенденция меняется, предприятий регистрируется меньше на $10 \%$. На общем фоне юридических лиц подавляющее число предприятий в РФ осуществляют свою деятельность в форме обществ с ограниченной ответственностью (ООО).

В 2008 году ООО было $71 \%$ от общего количество юридических лиц, к 01.01.2016 обществ с ограниченной ответственностью уже 82 \% от общего числа организаций. К 2018 году сокращается общее количество регистрируемых юридических лиц и пропорционально снижается количество регистрируемых обществ с ограниченной ответственностью, их преобладающее численность при этом сохраняется - 82 \% от общего количества [18]. 
Таблица 1

Количество юридических лиц, сведения о которых содержатся в Едином государственном реестре юридических лиц (ЕГРЮЛ) РФ по состоянию на 01.01.2008; 01.01.2015; 01.01.2016; 01.01.2017; 01.01.2018

\begin{tabular}{|l|c|c|c|c|c|}
\hline \multicolumn{1}{|c|}{ Показатель } & 01.01 .2008 & 01.01 .2015 & 01.01 .2016 & 01.01 .2017 & 01.01 .2018 \\
\hline $\begin{array}{l}\text { Юридические лица, запись о } \\
\text { которых внесена в ЕГРЮЛ } \\
\text { (кроме юридических лиц, } \\
\text { прекративших свою деятель- } \\
\text { ность), всего }\end{array}$ & 3634821 & 4659623 & 4820432 & 4553818 & 4371335 \\
\hline $\begin{array}{l}\text { Количество коммерческих } \\
\text { организаций }\end{array}$ & 3012835 & 3991137 & 4150374 & 3895974 & 3729191 \\
\hline $\begin{array}{l}\text { Количество обществ с огра- } \\
\text { ниченной ответственностью }\end{array}$ & 2615804 & 3778274 & 3962627 & 3742114 & 3597536 \\
\hline $\begin{array}{l}\text { Количество акционерных } \\
\text { обществ }\end{array}$ & 194057 & 142366 & 126074 & 102293 & 86440 \\
\hline
\end{tabular}

Сокращение численности ООО с 2016 года отражает общую тенденцию к снижению количества вновь регистрируемых предприятий, так как подавляющее число существует в организационно-правовой форме ООО (рисунок).

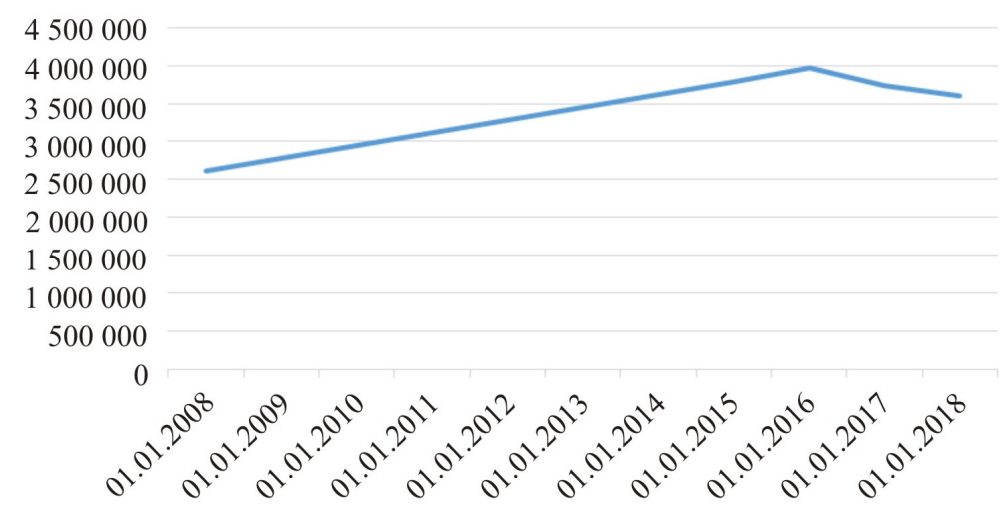

Рис. Количество обществ с ограниченной ответственностью, сведения о которых содержатся в ЕГРЮЛ на период 01.01.2008 - 01.01.2018

Организационно-правовая форма предприятия влияет на его правовой статус и характер имущественных отношений. В самом наименовании организационно-правовой формы ООО содержится информация об ограниченности ответственности ведения бизнеса. Очевидными преимуществами данной формы считаются простота государственной регистрации и возможности минимизации личной ответственности управляющего лица. Но опыт ведения бизнеса в РФ свидетельствует, что такое понимание организационноправовой формы ООО уходит в прошлое. 
С начала 2000-х годов законодательство в сфере ответственности руководителей/собственников плавно движется в сторону ужесточения. В начале ужесточили условия купли-продажи доли, обязав заключать нотариальный договор, затем ввели ответственность за брошенные фирмы, увеличили количество оснований для административного исключения из ЕГРЮЛ.

По данным ЕГРЮЛ субъектов малого и среднего предпринимательства можно отметить стабильный постепенный рост субъектов малого и среднего предпринимательства до 2016 года. При этом растет количество исключенных компаний, за 2015 год их число составляло 172 201, за 2016 год это число значительно выросло и составляло 591 315. За период с 01.01.2017 по 01.01.2018 количество юридических лиц, прекративших деятельность в отчетном периоде, составило 607088 [18]. Очевиден поступательный тренд, свидетельствующий о росте темпов выхода из бизнеса, но с тенденцией некоторой стабилизации количества выходящих.

Общее количество юридических лиц, прекративших свою деятельность на 01.01.2018, уже превышает количество действующих юридических лиц. В частности, количество обществ с ограниченной ответственностью, прекративших свою деятельность, превышает число зарегистрированных. Сравнительные данные представлены в табл. 2 [18].

Таблица 2

Количество юридических лиц, сведения о которых содержатся в ЕГРЮЛ РФ по состоянию на 01.01.2018

\begin{tabular}{|l|c|c|c|c|}
\hline \multicolumn{1}{|c|}{ Показатель } & $\begin{array}{c}\text { Юридические } \\
\text { лица, запись о } \\
\text { которых вне- } \\
\text { сена в ЕГРЮЛ } \\
\text { на 01.01.2018 }\end{array}$ & $\begin{array}{c}\text { Юридические } \\
\text { ливар прекра- } \\
\text { деятельность } \\
\text { на } 01.01 .2018\end{array}$ & $\begin{array}{c}\text { Абсо- } \\
\text { лютные } \\
\text { изене- } \\
\text { ния }\end{array}$ & $\begin{array}{c}\text { Темп при- } \\
\text { роста выбы- } \\
\text { вающих ор- } \\
\text { ганизаций, } \\
\%\end{array}$ \\
\hline $\begin{array}{l}\text { Количество юридических } \\
\text { лиц, сведения о которых со- } \\
\text { держатся в ЕГРЮЛ, всего }\end{array}$ & 4371335 & 5855275 & 1483940 & 33 \\
\hline $\begin{array}{l}\text { Коммерческие организации, } \\
\text { всего }\end{array}$ & 3729191 & 5168073 & 1438882 & 38 \\
\hline $\begin{array}{l}\text { Общества с ограниченной } \\
\text { ответственностью }\end{array}$ & 3597536 & 4396254 & 798718 & 22 \\
\hline
\end{tabular}

В рамках реформы контроля и надзора осуществляется расширение границ субсидиарной ответственности, ужесточение условий ведения бизнеса. Широкое распространение получило привлечение к субсидиарной ответственности при банкротстве предприятий. В 2002 году в соответствии с Ф3 «О несостоятельности (банкротстве)» привлечение собственников, руководителей к субсидиарной ответственности скорее было исключением из правил. 
30 июля 2017 года вступили в действие два пакета поправок, разработанных Правительством, они должны помочь сделать субсидиарную ответственность рабочим эффективным механизмом. Первый пакет поправок (№ 488-Ф3 от 28 декабря 2016 года) приняли еще в конце 2016 года. Он устанавливает ответственность даже за пределами банкротства, если, например, на него не хватает денег, в частности, когда «бросили» фирму-однодневку. Кредиторы получили право привлечь контролирующее лицо к ответу после окончания конкурсного производства. Им на это дали дополнительно три года, если промедление объясняется объективными причинами (например, обстоятельства виновности бенефициара стали известны позже).

Второй пакет поправок (№ 266-Ф3 от 29 июля 2017 года) переносит на бенефициаров бремя доказывания своей невиновности и упрощает кредиторам задачу привлечения к ответственности. В связи с внесенными изменениями в законодательство доказать свою невиновность и избежать субсидиарной ответственности становится все труднее и сложнее. Для снижения рисков привлечения к данному виду ответственности руководителям, учредителям и другим контролирующим лицам необходимо применять превентивные меры, например:

- избегать продажи активов организации по заниженной цене;

- не заключать заведомо невыгодные сделки с аффилированными лицами, фиктивные сделки;

- в случае утраты финансовых, бухгалтерских документов предпринимать активные меры по их восстановлению;

- проявлять должную осмотрительность и осторожность при выборе контрагентов [19].

К субсидиарной ответственности с 2018 года по ст. 399 ГК РФ можно привлечь руководителя/собственника даже в том случае, если они не подали заявление о банкротстве, хотя были обязаны это сделать, понимая, что организация не может исполнить свои обязательства и всех активов не хватит для погашения существующей кредиторской задолженности. Субсидиарная ответственность касается всех без исключения, будь ты простой бизнесмен или федеральное министерство [20].

Количество процедур банкротства ежегодно растет, процедура позволяет безболезненно расстаться с долгами. По статистике ФНС, 70 \% банкротств не дают положительного для экономики страны результата, хотя тенденция к увеличению взыскиваемых сумм прослеживается.

В целом можно говорить, что, с одной стороны, в РФ сложилась определенная инфраструктура поддержки развития малого предпринимательства на федеральном уровне и на уровне субъектов Федерации. С другой стороны, очевидно, малый бизнес подвергается законодательному давлению со стороны государства, принимаемые нормы направлены на то, чтобы облегчить ра- 
боту налоговой инспекции и упростить процедуру взыскания долгов организаций перед бюджетом за счет субсидиарной ответственности.

Повышение эффективности налогового администрирования способствует наполнению бюджета, а также сокращению теневого сектора, выравниванию условий конкуренции, снижению коррупции и в долгосрочном плане повышению эффективности экономики. Рычагом регулирования за счет аналитических средств при новой модели налогового администрирования, в основе которой лежит современная технология Big Data, стала регистрация бизнеса.

Реализация отраслевого подхода простимулировала налогоплательщиков к корректировке своих обязательств, внедрение АСК НДС-2 и онлайн ККТ способствовали развитию риск-ориентированного контроля. Сложился с 2015 года устойчивый тренд: количество проверок сокращается благодаря автоматизированной проверке, но собираемость и доначисления растут, идет сокращение прямых налогов и рост косвенных, что соответствует практике стран ОЭСР.

Реформирование налогового администрирования в России привело к снижению нагрузки на налоговые органы, к упрощению налогового контроля, но ужесточение субсидиарной ответственности снижает уровень деловой активности в среде малого и среднего бизнеса. Дальнейшее развитие практики налогового администрирования должно основываться на результатах анализа, полученного по материалам горизонтального мониторинга, и предусматривать экономические последствия влияния на все сферы экономики.

\section{Список литературы}

1. Чапкина Н.А. Оценка эффективности контрольной работы ФНС России за 2013 - 2017 // Налоги и налогообложение. - 2018. - № 4. - С. 26-39.

2. Толстоброва Н.А., Климова Е.К. Реконструкция концепции планирования налоговых проверок согласно ст.54.1 НК РФ // Проблемы экономики и юридической практики. - 2018. - № 2. - С. 137-142.

3. Совершенствование системы налогового администрирования в России / В.А. Цветков, А.А. Шутьков, М.Н. Дудин, Н.В. Лясников // Финансы: Теория и Практика. - 2017. - Т. 21, № 6. - С. 34-49.

4. Козенкова Т.А., Тетерятникова К.С. Зарубежный опыт стимулирования экономики посредством налогового регулирования // Российский экономический журнал. - 2018. - № 3. - С. 83-92.

5. Яблоков Д.Ю. Методика оценки влияния некоторых факторов на уровень налогового администрирования в России при переходе к цифровой экономике // Налоги и налогообложение. - 2018. - № 5. - С. 53-62.

6. Прыгунова М.И., Никифорова Э.Г. Ретроспективный анализ деятельности основных органов государственной поддержки малого и среднего 
предпринимательства в России // Менеджмент в России и за рубежом. 2018. - № 5. - С. 28-35.

7. Тонких А.С., Трушин И.И. Разработка критерия экономической целесообразности для предпроверочного анализа налогоплательщиков // Налоги и налогообложение. - 2018. - № 4. - C. 58-73.

8. Almunia M., Lopez-Rodriguez D. Under the radar: The Effects of monitoring firms on tax compliance // American Economic Journal: Economic Policy. 2018. - No. 10 (1). - Р. 1-38.

9. Бородин И., Кудрявцев Ф. Управление налоговыми рисками в условиях финансового кризиса [Электронный ресурс]. - URL: https://fd.ru/articles/36218upravlenie-nalogovymi-riskami-v-usloviyah-finansovogo-krizisa (дата обращения: 12.11.2018).

10. Федеральная налоговая служба. Налоговая аналитика. За счет чего растут налоговые поступления. - URL: https:/analytic.nalog.ru/portal/analytical_ information.ru-RU.htm (дата обращения: 19.11.2018).

11. Публичная декларация целей и задач ФНС России на 2018 год. URL: https:/www.nalog.ru/html/sites/www.new.nalog.ru/docs/about.../publdecl 2018.ppt (дата обращения: 19.11.2018).

12. Контроль и надзор - как не удавить бизнес без вреда для потребителей - OTP. - URL: https://otr-online.ru/programmy/prav-da/kontrol-i-nadzor28047.html (дата обращения: 10.10.2018).

13. Бархатов В.И., Белова И.А. Государственные программы поддержки малых и средних предприятий в России // Вестник Пермского национального исследовательского политехнического университета. Социально-экономические науки. - 2017. - № 1. - С. 208-223.

14. Владимир Путин поручил продлить надзорные каникулы. - URL: https://rg.ru/2018/10/23/putin-poruchil-prodlit-nadzornye-kanikuly-dlia-malogobiznesa.html (дата обращения: 26.10.2018).

15. Паспорт национального проекта (программы) «Малое и среднее предпринимательство и поддержка индивидуальной предпринимательской инициативы»: [проект (по состоянию на 31.08.2018)]. - URL: https: //www.midural.ru/download.php?id=_20187311512.pdf (дата обращения: 10.10.2018).

16. Кадомцева М.Е. Налоговое сопровождение этапов инновационного процесса // Вестник Пермского национального исследовательского политехнического университета. Социально-экономические науки. - 2018. - № 1. C. $230-241$.

17. О рекомендациях по применению положений статьи 54.1 Налогового кодекса Российской Федерации: Письмо ФНС России от 31.10.2017 № ЕД4-9/22123@. - URL: http:/www.garant.ru/products/ipo/prime/doc/71702272/ (дата обращения: 27.03.2018). 
18. Статистика по государственной регистрации ЮЛ и ИП в целом по Российской Федерации. Сведения о работе по государственной регистрации юридических лиц по состоянию на 01.01.2008; 01.01.2015; 01.01.2016; 01.01.2017; 01.01.2018. - URL: https://www.nalog.ru/rn77/related_activities/ statistics_and_analytics/regstats/ (дата обращения: 23.10.2018).

19. Субсидиарная ответственность в 2018 году. Почему расстаться с бизнесом станет еще сложнее. - URL: https://www.klerk.ru/boss/articles/ 471621/ (дата обращения: 08.10.2018).

20. Гражданский кодекс Российской Федерации (часть первая) от 30.11.1994 № 51-ФЗ (ред. от 03.08.2018) (с изм. и доп., вступ. в силу с 01.09.2018). - Ст. 399. Субсидиарная ответственность. - URL: https://www.consultant.ru/document/.../27b86799156af774a4d2d3e3fa70deecdaec d768/ (дата обращения: 23.10.2018).

\section{References}

1. Chapkina N.A. Otsenka effektivnosti kontrol'noi raboty FNS Rossii za 20132017 [Evaluation of the efficiency of control activities of the Federal Tax Service of Russia for 2013-2017]. Nalogi i nalogooblozhenie, 2018, no. 4, pp. 26-39.

2. Tolstobrova N.A., Klimova E.K. Rekonstruktsiia kontseptsii planirovaniia nalogovykh proverok soglasno st.54.1 NK RF [Reconstruction of the concept of tax check planning according to CL.54.1 of the tax code of the Russian Federation]. Problemy ekonomiki i iuridicheskoi praktiki, 2018, no. 2, pp. 137-142.

3. Tsvetkov V.A., Shut'kov A.A., Dudin M.N., Liasnikov N.V. Sovershenstvovanie sistemy nalogovogo administrirovaniia v Rossii [Improvement of the tax administration system in Russia]. Finansy: Teoriia i Praktika, 2017, vol. 21, no. 6, pp. 34-49.

4. Kozenkova T.A., Teteriatnikova K.S. Zarubezhnyi opyt stimulirovaniia ekonomiki posredstvom nalogovogo regulirovaniia [International practice of boosting economy through taxation policy]. Rossiiskii ekonomicheskii zhurnal, 2018, no. 3, pp. 83-92.

5. Iablokov D.Iu. Metodika otsenki vliianiia nekotorykh faktorov na uroven' nalogovogo administrirovaniia $\mathrm{v}$ Rossii pri perekhode $\mathrm{k}$ tsifrovoi ekonomike [Methodology of assessing the impact of some factors on the tax administration system in Russia in the transition to the digital economy]. Nalogi $i$ nalogooblozhenie, 2018, no. 5, pp. 53-62.

6. Prygunova M.I., Nikiforova E.G. Retrospektivnyi analiz deiatel'nosti osnovnykh organov gosudarstvennoi podderzhki malogo i srednego predprinimatel'stva v Rossii [Retrospective analysis of the activity of the major bodies of government support of small and medium-sized businesses in Russia]. Menedzhment $v$ Rossii i za rubezhom, 2018, no. 5, pp. 28-35. 
7. Tonkikh A.S., Trushin I.I. Razrabotka kriteriia ekonomicheskoi tselesoobraznosti dlia predproverochnogo analiza nalogoplatel'shchikov [Development of cost-effectiveness criterion for pre-verification analysis of the taxpayers]. Nalogi i nalogooblozhenie, 2018, no. 4, pp. 58-73.

8. Almunia M., Lopez-Rodriguez D. Under the Radar: The Effects of Monitoring Firms on Tax Compliance. American Economic Journal: Economic policy, 2018, no. 10 (1), pp. 1-38.

9. Borodin I., Kudriavtsev F. Upravlenie nalogovymi riskami v usloviiakh finansovogo krizisa [Tax risk management in the conditions of financial crisis]. Available at: https://fd.ru/articles/36218-upravlenie-nalogovymi-riskami-vusloviyah-finansovogo-krizisa (accessed 12 November 2018).

10. Federal'naia nalogovaia sluzhba. Nalogovaia analitika. Za schet chego rastut nalogovye postupleniia [Federal income tax. Tax analytics. The sources of increased tax revenues]. Available at: https://analytic.nalog.ru/portal/analytical_ information.ru-RU.htm (accessed 19 November 2018).

11. Publichnaia deklaratsiia tselei i zadach FNS Rossii na 2018 god [Public declaration of purposes and tasks of Federal Tax Service of Russia for 2018]. Available at: https://www.nalog.ru/html/sites/www.new.nalog.ru/docs/about.../ publdec12018.ppt (accessed 26 October 2018).

12. Kontrol' i nadzor - kak ne udavit' biznes bez vreda dlia potrebitelei OTR [Monitoring and oversight - how not to strangle business for consumers OTR]. Available at: https://otr-online.ru/programmy/prav-da/kontrol-i-nadzor28047.html (accessed 10 October 2018).

13. Barkhatov V.I., Belova I.A. Gosudarstvennye programmy podderzhki malykh i srednikh predpriiatii v Rossii [State support programs for small and medium-sized enterprises in Russia]. PNRPU Sociology and Economics Bulletin, 2017, no. 1, pp. 208-223.

14. Vladimir Putin poruchil prodlit' nadzornye kanikuly [Vladimir Putin instructed to prolong supervision holidays]. Available at: https://rg.ru/2018/10/23/ putin-poruchil-prodlit-nadzornye-kanikuly-dlia-malogo-biznesa.html (accessed 26 October 2018).

15. Pasport natsional'nogo proekta (programmy) "Maloe i srednee predprinimatel'stvo i podderzhka individual'noi predprinimatel'skoi initsiativy" [Passport of the national project (program) "Small and medium-sized businesses and support of individual entrepreneurial initiative"]. Project of 31 August 2018]. Available at: https://www.midural.ru/download.php?id=_20187311512.pdf (accessed 10 October 2018).

16. Kadomtseva M.E. Nalogovoe soprovozhdenie etapov innovatsionnogo protsessa [Tax support at innovative process stages]. PNRPU Sociology and Economics Bulletin, 2018, no. 1, pp. 230-241. 
17. O rekomendatsiiakh po primeneniiu polozhenii stat'i 54.1 Nalogovogo kodeksa Rossiiskoi Federatsii [On recommendations for the application of the provisions of Article 54.1 of the Tax Code of the Russian Federation]. Letter of Federal Tax Service of Russia of Oct. 31, 2017 no. ED-4-9/22123@. Available at: https: http://www.garant.ru/products/ipo/prime/doc/71702272/ (accessed 27 March 2018).

18. Statistika po gosudarstvennoi registratsii IUL i IP v tselom po Rossiiskoi Federatsii [Statistics on the state registration of legal persons and individual entrepreneurs]. Details of the work on the state registration of legal persons of Jan. 1, 2008, 2015, 2016, 2017, available at: https:/www.nalog.ru/rn77/related_activities/ statistics_and_analytics/regstats/(accessed 23 October 2018).

19. Subsidiarnaia otvetstvennost' v 2018 godu. Pochemu rasstat'sia s biznesom stanet eshche slozhnee [Residual liability in 2018. Why will it be even more difficult to get rid of business]. Available at: https://www.klerk.ru/boss/articles/ 471621/ (accessed 08 October 2018).

20. Grazhdanskii kodeks Rossiiskoi Federatsii (chast' pervaia) ot 30.11 .1994 № 51-FZ (red. ot 03.08.2018) (s izm. i dop., vstup. v silu s 01.09.2018). St. 399. Subsidiarnaia otvetstvennost' [Civil Code of the Russian Federation (part 1) of Nov. 30, 1994 no. 51-FZ, rev. August 03, 2018, rev. Sep.1, 2018. Art. 399. Subsidiary liability]. Available at: https://www.consultant.ru/document/../27b86799 156af774a4d2d3e3fa70deecdaecd768/ (accessed 23 October 2018).

Оригинальность $91 \%$

Получено 26.11.2018 Принято 21.12.2018 Опубликовано 28.06.2019

\author{
N.A. Tolstobrova, E.K. Klimova
}

\title{
INFLUENCE OF TOOLS OF FISCAL ADMINISTRATION ON BUSINESS ACTIVITY
}

\begin{abstract}
The study overviews the consequences of legislative changes in Russian business sphere presently evolving under sanctions when a need to liberalize business and increase business activity is accompanied by the activation of tax administration. The major avenue in the field of fiscal administration is to improve the efficiency of the tax system, control and supervision activities and regulatory specification of organizational and legal forms of business. A more rigid interpretation of the conditions for operating a limited liability company repulses the population from doing business. With a tighter subsidiary liability coupled with the requirements of Article 54.1 of the Tax code state supervisory functions and fiscal burden expand.

The research draws on general scientific approaches, comparative and economic-statistical methods. The issues of state support of business are considered. The article analyzes an impact of state legislative and regulatory measures on the functioning of small and medium-sized businesses. Generalization and concretization of fiscal administration practices allowed to establish interrelation between registration of inclusion into/exclusion from the Unified State Register of Legal Entities and
\end{abstract}


Unified State Register of Sole Entrepreneurs with the statement principle of running a business. The introduction of technological innovations in the tax accounting system and expansion of subsidiary responsibility filtered out business actors who were nominally present in the state registers. The presented results of the analysis of statistical data indicate a reduction in the number of legal entities, LLC representing the major fraction. This may be explained by the optimized registration procedures for legal entities and increased efficiency of the bankruptcy procedure. Fiscal administration trends are summed up. A necessity of monitoring the entirety of state measures and factors affecting entrepreneurial activity is substantiated.

Keywords: tax control, fiscal administration, business registration, entrepreneurship, limited liability company, subsidiary liability.

Nadezhda A. Tolstobrova - Candidate of Economic Sciences, Associate Professor, Department of Economics and Finance, Perm National Research Polytechnic University, e-mail: tolstobrova@mail.ru.

Elena K. Klimova - Senior Lecturer, Department of Economics and Finance, Perm National Research Polytechnic University, e-mail: klimovalk@gmail.com.

Received 26.11.2018 $\quad$ Accepted 21.12.2018 $\quad$ Published 28.06.2019 